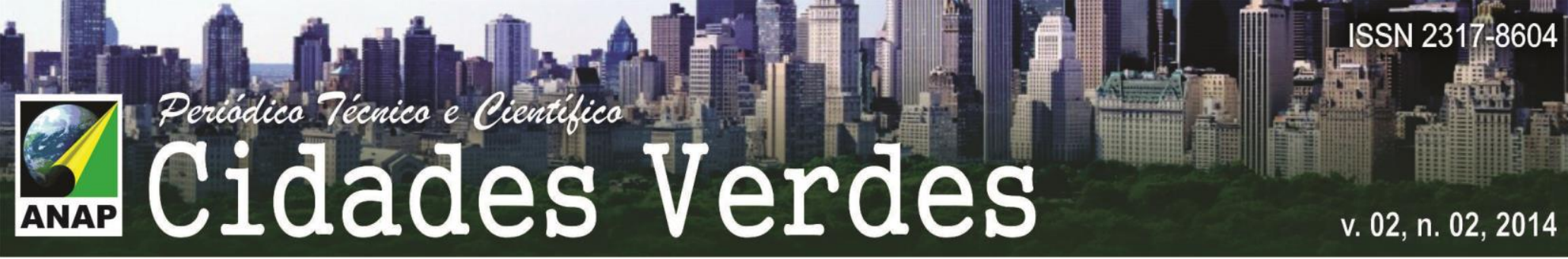

\title{
SUSTENTABILIDADE NA CIDADE
}

\author{
Nathalia da Mata Mazzonetto Pinto ${ }^{1}$
}

Gilda Collet Bruna ${ }^{2}$

\begin{abstract}
RESUMO
O artigo trata da questão ambiental. Focaliza a poluição atmosférica aumentada pela falta de urbanismo sustentável e deficiência de gestão ambiental urbana; esta situação leva em geral ao esgotamento de recursos naturais e a pouca qualidade de vida; mostra que as áreas verdes ainda não suprem a necessidade da população urbana. Mas também que há cidades que possuem iniciativas em prol de maior sustentabilidade.
\end{abstract}

PALAVRAS-CHAVE: sustentabilidade urbana; poluição; qualidade de vida.

\section{SUSTAINABILITY IN THE CITY}

\section{ABSTRACT}

This article is about environmental issues. It focus the atmospheric pollution increased by the lack of sustainable urbanism and insufficient urban environmental management; this situation leads in general to the scarcity of natural resources and low quality of life, which shows that green sites aren't still enough for the urban population needs, nevertheless there are cities that started new initiatives toward better sustainability. KEY-WORDS: Urban sustainability; pollution; quality of life.

\section{SOSTENIBILIDAD EN LA CIUDAD}

\footnotetext{
1. Graduanda pela Faculdade de Arquitetura e Urbanismo, Universidade Presbiteriana Mackenzie. 31306896@mackenzista.com.br

2 Doutora e Livre Docente pela Faculdade de Arquitetura e Urbanismo, Universidade de São Paulo. Professora da Faculdade de Arquitetura e Urbanismo, Universidade Presbiteriana Mackenzie. gilda@mackenzie.br
} 
os serviços urbanos ao fazer com que as pessoas precisem percorrer grandes distâncias. Por outro lado, a concentração populacional nas cidades aumenta a demanda de transporte público que, em muitos casos como em São Paulo, não consegue atender eficientemente a todos. Em decorrência, acaba incentivando o transporte individual, que por sua vez, ocasiona maior poluição atmosférica. Esse é praticamente um círculo vicioso que induz a espaços congestionados, áreas degradadas com os respectivos problemas de saúde.

No entanto, para a venda de petróleo, é preciso que exista uma necessidade maior que apenas a de locomoção. Isto porque é bastante viável transportar-se apenas através de transporte coletivo e deslocamento a pé quando se tem uma cidade adaptada para isso, ou seja, com um urbanismo sustentável. Estimulou-se a criação de cidades espraiadas que fazem com que seus habitantes precisem do automóvel e consumam petróleo para movimentar-se, não contando com áreas verdes que beneficiam a todos.

O fato de ser transporte individual vende uma ideia de conforto, e portanto, as pessoas em geral preferem usar o carro para se deslocar em detrimento do transporte público e da caminhada. Compras que poderiam ser feitas em lojas nas proximidades das residências, por exemplo, são ignoradas pelo fato de que com o uso do carro é possível percorrer maiores distâncias até um hipermercado ou centro comercial mais diversificado. O automóvel resume todo esse estilo de vida citado anteriormente. Nada mais é que o transporte individualizado com as pessoas isoladas em seus carros produzindo diversos poluentes liberados no ar.

Esta dependência criada pelo uso do carro gera altos custos, demandando a construção de estacionamentos e vias, o que exige grande investimento. Segundo pesquisa feita pelo Instituto de Pesquisas Econômicas Aplicadas (Ipea) em 2011, a cada $R \$ 1$ investido no transporte público brasileiro, $R \$ 12$ são investidos no transporte particular. ${ }^{6}$ Além disso, segundo Farr (2013), em locais com maior trânsito de automóveis existe maior liberação de $\mathrm{CO}_{2}$ e demais gases do efeito estufa. $\mathrm{O}$

\footnotetext{
${ }^{6}$ IPEA. R7.com: A cada R\$ 1 investido em transporte público, governo dá $\mathbf{R} \$ 12$ em incentivo para carro e moto. Disponível em< www.ipea.gov.br/portal/index.php?option=com content\&view=article\&id=8616\&catid=159\&ltemid=75 Acesso em 13 de junho de 2014 .
} 
a construção de habitação para o mercado das classes mais altas, sendo ocupados pelas favelas e a cidade-informal, que diferente da cidade-formal, não recebe o mesmo tratamento estabelecido pelas normas da cidade e do país, principalmente em relação ao acesso a saneamento básico. O descarte irregular de lixo e a dificuldade de acesso à água "cultivam" um ambiente propício a um grande número de doenças. Relembrando, estes locais íngremes, somados à retirada da cobertura vegetal para a construção de residências, são bastante propensos a deslizamentos de terra, pondo em risco a vida de muitas pessoas.

Desse modo, é possível observar um crescimento na população que mora em áreas de risco durante a história do Brasil. Segundo o Instituto de Pesquisa Econômica Aplicada (Ipea), no ano 2000 a população brasileira favelada no Brasil era de 10,6 milhões de habitantes, enquanto em 2010 esse número cresceu para 11,2 milhões. $^{13}$ No entanto, não existe a mesma velocidade nas ações governamentais para impedir que estas pessoas corram este risco ambiental. A questão da habitação social, infelizmente, está muito longe na escala de melhoria da qualidade da cidade. As classes mais altas são melhor atendidas enquanto a população carente continua sendo realocada para locais com mínima qualidade.

Muitas cidades pelo mundo têm alterado suas legislações e criado mecanismo a fim de obter menores índices de liberação de gases poluentes, menor impacto ambiental e melhor qualidade de vida para seus habitantes. No Brasil, apesar das dificuldades sociais típicas de um país em desenvolvimento, também existem casos de sucesso onde os princípios do Urbanismo Sustentável têm sido aplicados. O município de São Caetano do Sul, no estado de São Paulo, apresenta o melhor Índice de Desenvolvimento Humano do país segundo levantamento feito pela $\mathrm{ONU}^{14}$, publicado em 2013, além de ter recebido a certificação Município Verde Azul, programa da Secretaria do Meio Ambiente do Estado de São Paulo que estimula a implantação de ações em prol do meio ambiente. Em São Caetano do Sul a sustentabilidade se faz presente na constante plantação e manutenção das

13 IPEA. Destaques do Cidade em Movimento (02/12). Disponível em < http://www.ipea.gov.br/portal/images/stories/PDFs/presi/131202_coletivacidadesrelease.pdf > Acesso em 7 de julho de 2014.

14 PNUD. Ranking IDHM Municípios 2010. Disponível em < http://www.pnud.org.br/atlas /ranking/Ranking-IDHM-Municipios-2010.aspx > Acesso em 22 de julho de 2014. 


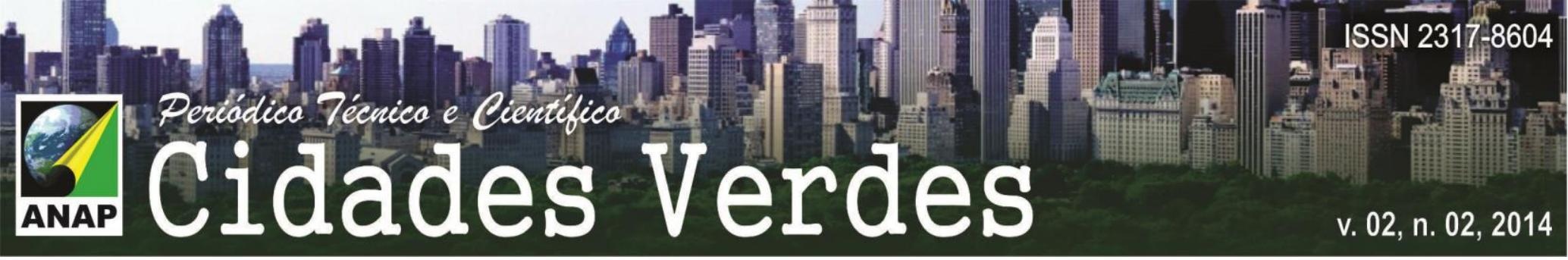

árvores e projetos paisagísticos para criar espaços agradáveis e com senso de lugar, estimulando a conexão entre os habitantes e o meio ambiente. O programa Coleta Seletiva de Lixo estimula a participação da comunidade no objetivo sustentável da cidade. Além disso, a instalação de ciclovias oferece mais opções de transporte pelo município, alternativa limpa e econômica. ${ }^{15}$

Figura 1: Av. Pres. Kennedy, São Caetano do Sul

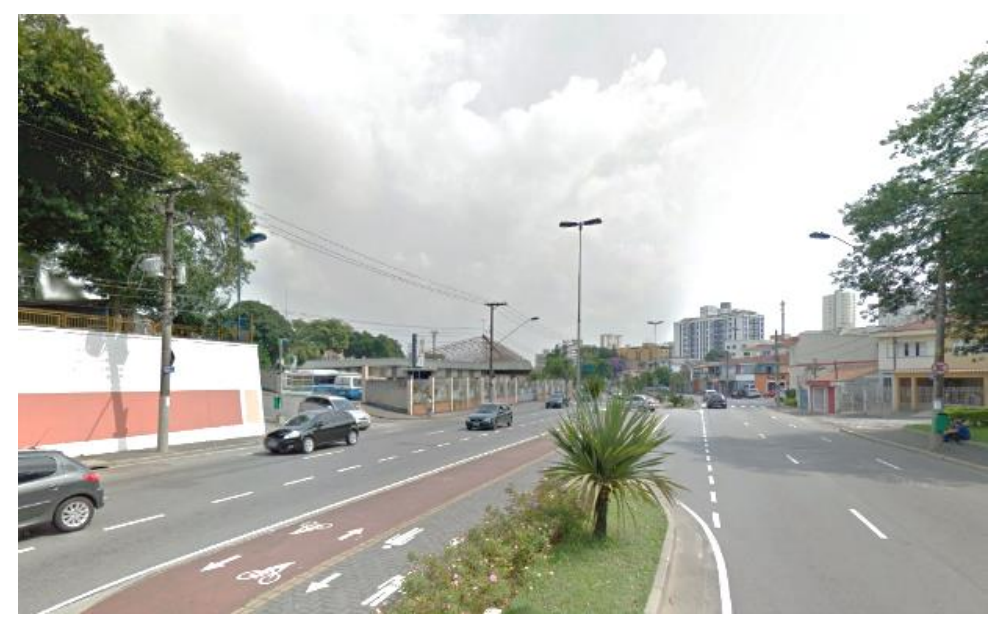

FONTE: Google Maps, 2013

Figura 2: Av. Pres. Kennedy, São Caetano do Sul

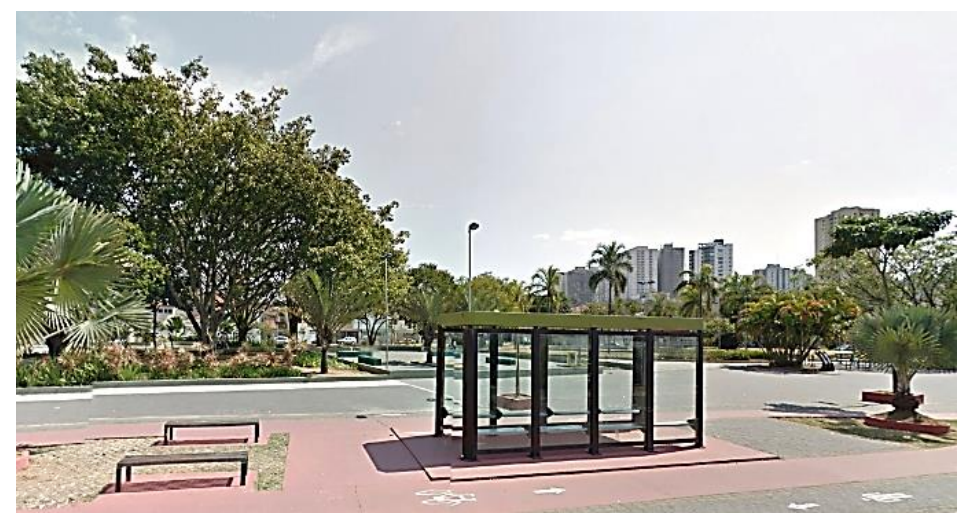

FONTE: Google Maps, 2013

PREFEITURA DE SÃO CAETANO DO SUL. Departamento de Meio Ambiente e Sustentabilidade. Disponível em <http://www.saocaetanodosul.sp.gov.br/secretarias/servicosurbanos/departamento-de-meio-ambiente-e-sustentabilidade1.html> Acesso em 22 de julho de 2014. 


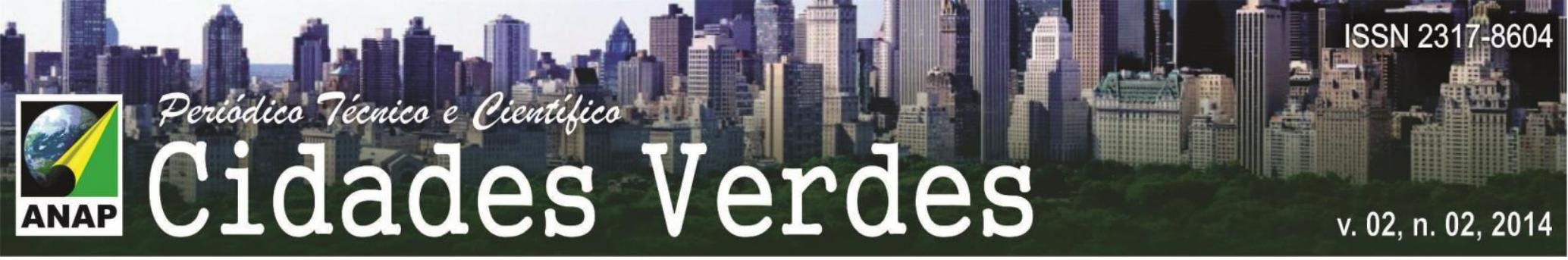

Figure 3: Coleta Seletiva, São Caetano do Sul

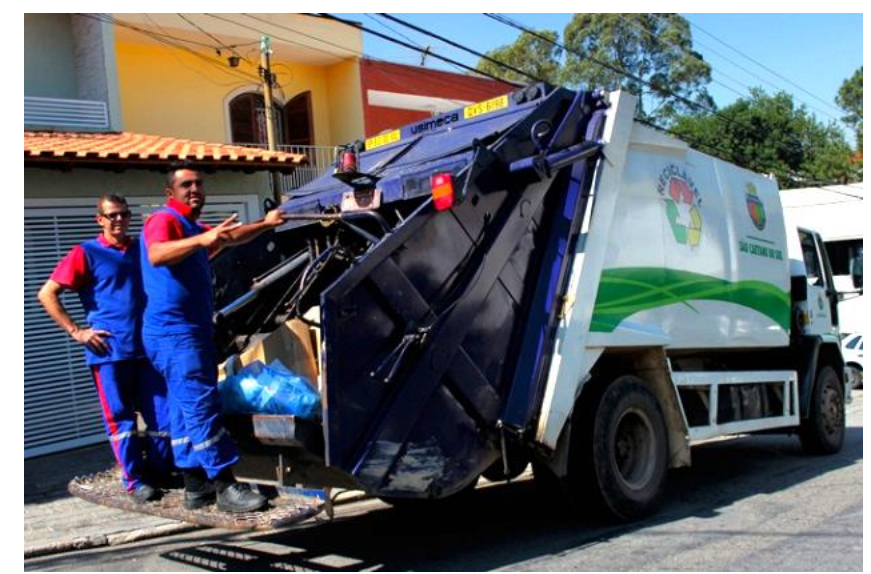

FONTE: DAE/SC, 2014

A cidade de Curitiba, no Paraná, tem o décimo melhor IDH do Brasil e é cidade sustentável premiada pela United Nations Environment Programme (Unep) em 1990 por representar o maior uso de transporte público e menor índice de poluição do país. Além disso, a cidade é bastante arborizada e possui parques lineares ao longo dos rios, evitando enchentes na região, programas de coleta de lixo e área industrial na qual só podem ser instaladas indústrias que estejam engajadas nas questões sustentáveis. ${ }^{16}$

Figura 4: Jardim Botânico, Curitiba

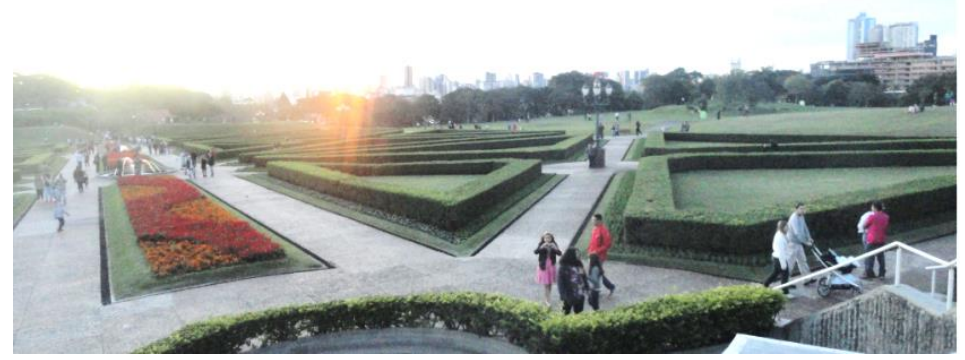

FONTE: Nathalia da Mata Mazzonetto Pinto, 2013.

\footnotetext{
${ }^{16}$ UNITED NATIONS ENVIRONMENT PROGRAM (UNEP). Sustainable Urban Planning in Brazil. Disponível em < http://www.unep.org/greeneconomy/SuccessStories/Sustainaible UrbanPlanninginBrazil/tabid/29867/Default.aspx> Acesso em 2 de março de 2014.
} 


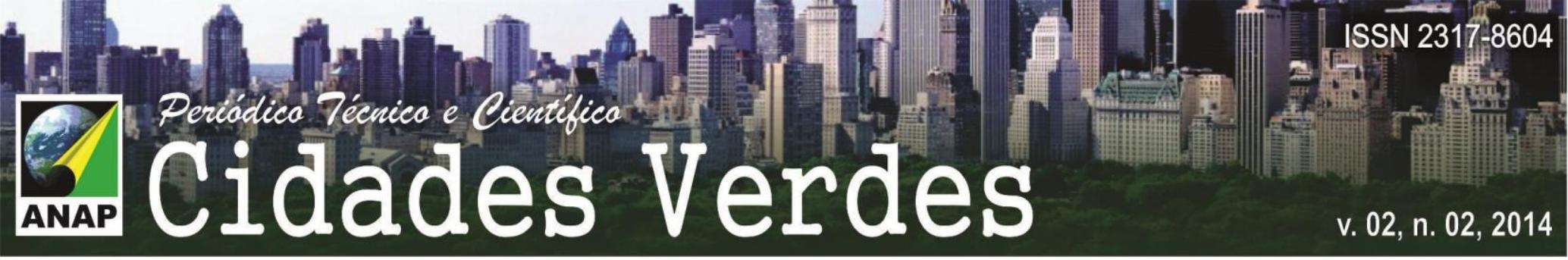

parques pela cidade até $2020 .^{20}$ Iniciativas como estas são bastante semelhantes aos princípios do movimento Smart Growth, que propõe melhorias nos espaços públicos, preservações dos espaços abertos e estimular a colaboração da população.

Figura 5: Stanley Park, Vancouver

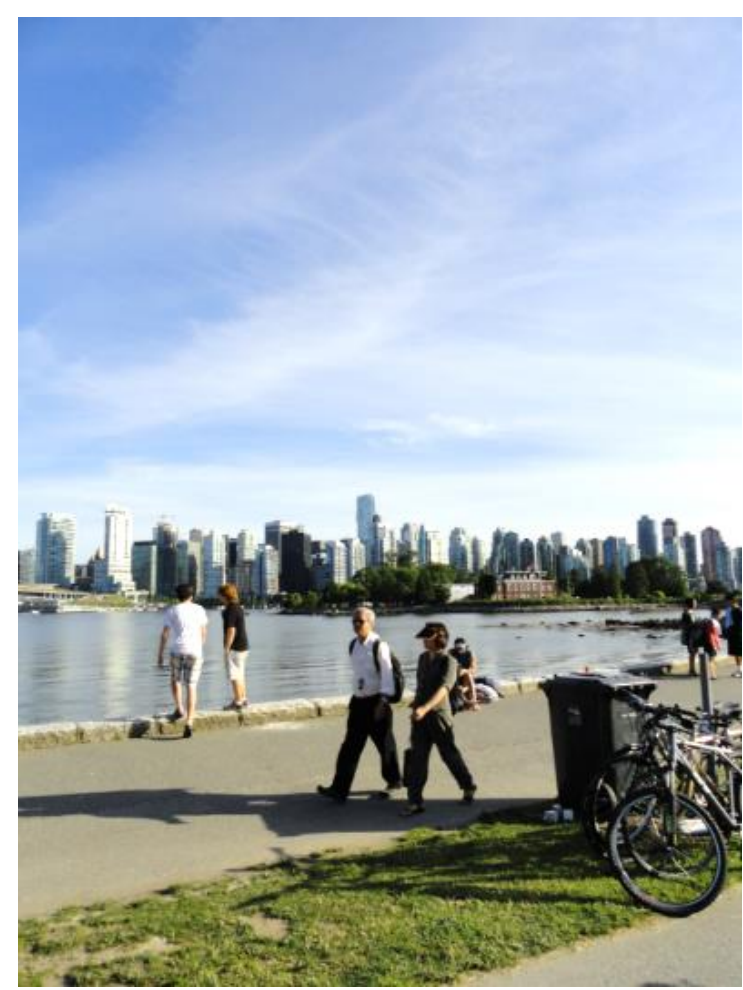

FONTE: Nathalia da Mata Mazzonetto Pinto, 2011

\section{CONCLUSÃO}

Pode-se entender que esse artigo mostra a importância do urbanismo para as populações das cidades. Estas contam com proposições para a criação de um urbanismo inteligente, que em outras palavras prevê: estruturas de mobilidade para a população; desenho urbano com a natureza; variedade de áreas verdes, o que leva a melhores resultados de qualidade de vida; diminuição da poluição apoiada as

20 CITY OF VANCOUVER. Greenest City 2020 Action Plan. Disponível em < http://vancouver.ca/green-vancouver/greenest-city-2020-action-plan.aspx> Acesso em 22 de julho de 2014 


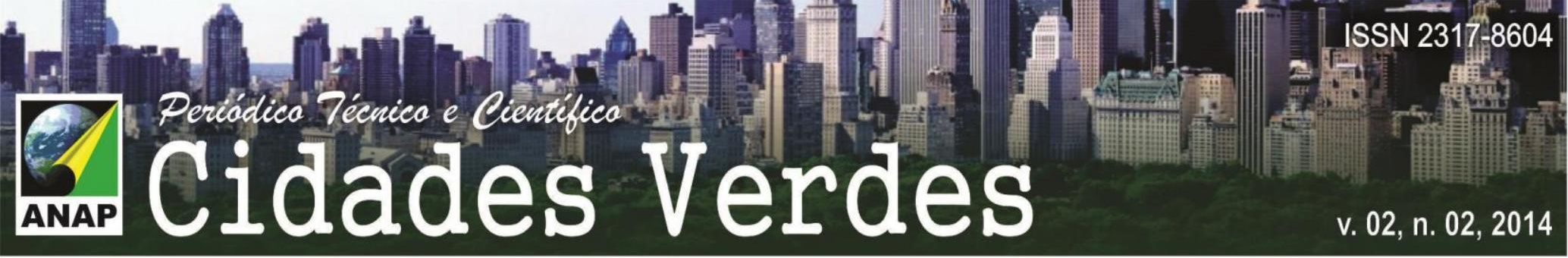

áreas verdes que vêm sendo propostas. Pode-se observar essas questões também pela premiação no Brasil de algumas cidades urbanizadas por organizações internacionais, como a ONU, WWF, entre outras. Assim, certas áreas urbanas brasileiras podem ser comparadas a de outras cidades estrangeiras, na medida que providenciem coleta, tratamento de resíduos sólidos e fonte de energia renovável e transportes público e alternativo adequados.

\section{REFERÊNCIAS}

BRASIL. Constituição (1988). TítuloVIII: Da Ordem Social, Capítulo VI: Do Meio Ambiente, artigo 225. Disponível em < http://www.senado.gov.br/legislacao/const/con1988/con1988_05.10.1988 lart_225_.shtm > Acesso em 06 de julho de 2014

CITY OF VANCOUVER. Greenest City 2020 Action Plan. Disponível em < http://vancouver.ca/green-vancouver/greenest-city-2020-action-plan.aspx> Acesso em 22 de julho de 2014

FARR, Douglas. Urbanismo Sustentável. Porto Alegre: Bookman, 2013.

GOLDEMBERG, José. 4 - Energia e Desenvolvimento Sustentável - Série Sustentabilidade. Ed. Blucher, 2010. Disponível em < http://www.blucher.com.br/editor/amostra/05708.pdf > Acesso em 31 de julho de 2014.

IPEA. Destaques do Cidade em Movimento (02/12). Disponível em < http://www.ipea.gov.br/portal/images/stories/PDFs/presi/131202_coletivacidadesrelease.pdf > Acesso em 7 de julho de 2014 .

IPEA. R7.com: A cada R\$ 1 investido em transporte público, governo dá $\mathbf{R} \$ 12$ em incentivo para carro e moto. Disponível em< www.ipea.gov.br/portal/index.php?option=com content\&view=article\&id=8616\&catid=159\&ltemid=75. Acesso em 13 de junho de 2014.

KEELER, Marian; BURKE, Bill. Fundamentos de projeto de edificações sustentáveis. Porto Alegre: Bookman, 2010.

LYNCH, Kevin. A imagem da cidade. 3. ed. São Paulo: Martins Fontes, 2011.

MINISTÉRIO DO MEIO AMBIENTE. Compromisso pela Qualidade do Ar e Saúde Ambiental. Disponível em < http://www.mma.gov.br/estruturas/163/_arquivos/compromisso2_163.pdf> Acesso em 13 de junho de 2014.

PESTANA. Liliane Moraes. A Agenda Marrom: O Planejamento Ambiental/ Brown Agenda: The Environmental Urban Plan. Revista de Direito a Cidade. Rio de Janeiro, V. 1, N. 1 (2006). Disponível em < http://www.e-publicacoes.uerj.br/index.php/rdc/issue/view/760> Acesso em 13 de Maio de 2014.

PREFEITURA DE BELO HORIZONTE. Cidade Sustentável. Disponível em < http://www.belohorizonte.mg.gov.br/bh-primeira-vista/belo-horizonte-cidade-sustentavel> Acesso em 22 de julho de 2014. 


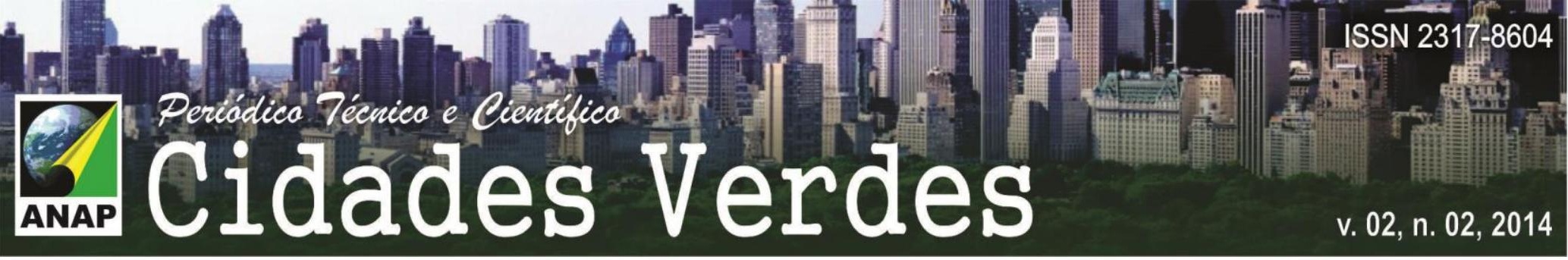

PREFEITURA DE SÃO CAETANO DO SUL. Departamento de Meio Ambiente e Sustentabilidade. Disponível em <http://www.saocaetanodosul.sp.gov.br/secretarias/servicos-urbanos/departamentode-meio-ambiente-e-sustentabilidade1.html> Acesso em 22 de julho de 2014.

UNITED NATIONS. Our Common Future, Chapter 1: A Threatened Future. Disponível em <http://www.un-documents.net/ocf-01.htm> Acesso em 1 de maio de 2014.

UNITED NATIONS ENVIRONMENT PROGRAM (UNEP). Sustainable Urban Planning in Brazil. Disponível em < http://www.unep.org/greeneconomy/SuccessStories/SustainaibleUrban PlanninginBrazil/tabid/29867/Default.aspx> Acesso em 2 de março de 2014.

VARELLA, Dráuzio. Conforto e Saúde. Disponível em < http://drauziovarella.com.br/ diabetes/conforto-e-saude/> Acesso em 13 de junho de 2014

WORLD GREEN BUILDING COUNCIL. WorldGBC Government Leadership Awards: Excellence in City Policy for Green Building. Disponível em < http://www.worldgbc.org/activities/govtleadership-awards/> Acesso em 22 de julho de 2014 